\title{
'Undesirable Relationships' between Jewish Women and Arab Men: Representation and Discourse in Contemporary Israel
}

Key words: Israel, inter-faith marriage, moral panic, Jews, Arabs

\author{
Dr. Yohai Hakak
}

Abstract:

Demography has been broadly considered as a key aspect of the Israeli-Palestinian conflict. On the Jewish side, State intervention to encourage Jewish immigration and Jewish births is well known. Much less known are the efforts to discourage inter-faith relations. These 'problematic relationships' between Arab men and Jewish women from low socio-economic backgrounds have become a high priority item in public discussions over the last decade. In this article I will explore the main discursive practices used in this heated debate by those opposing these relationships. 'Moral panic' as a theoretical framework will help me analyse the ways in which Jewish women and Arab men who engage in such relations are presented. As I will show, attempts to criminalize and vilify Arab men meet with strong opposition. Presenting Jewish women as weak and passive victims seems as a more successful strategy, especially when done by professionals from the psych professions. ${ }^{1}$

Media attention coverage of mixed-faith relationships in Israel has disproportionately focused on negative aspects. Marital violence in Jewish-Arab couples has gained exceptional media attention in Israel during the last decade. Such outcomes of JewishArab relations were at the centre of a great number of TV programs, radio shows and newspaper articles. This media coverage almost always portrays these relations in very negative light. Some of these reports are accompanied by footage from 'rescue operations' of Jewish women who were in such relations. Such semi-military operations are carried out by the Jewish Ultra-Orthodox organisation 'Yad-Le'achim' (Hands to our Brothers, in Hebrew) or by Lehava ${ }^{2}$, another Orthodox organisation, both dedicated to fighting Jewish assimilation. Armed members of these organisations enter Palestinian territories or Arab areas in Israel and 'extract' Jewish women and their children who asked for help. Social workers employed by Yad-Le'achim operate a helpline for women and girls who are in relationships with Arab men. These social workers have a very negative view about these relationships. Yad Le'achim has a very strong online presence and it also distributes vast amounts of printed materials such as pamphlets and books aimed at 'informing the public' about 'the dangers entailed in such relations'. Yad 
Le'achim employed a public relations expert who coined the slogan 'your grandchild will be called Ahmed son of Sara' ${ }^{3}$. This slogan was used during a long campaign in 2010 preasurising businesses to either fire Arab male employees or ensure they don't come into direct contact with Jewish female employees or customers ${ }^{4}$. 'Ahmed son of Sara' became the 'code name' for the outcomes of Jewish-Arab couples indicating for many Israeli Jews the ultimate parental failure in ensuring the Jewishness to the next generation. Helping 'Ahmed son of Sarah' and their 'survivors' mothers became also the highlight of an extremely successful fund-raising campaign by Yad Le'achim that followed.

Under the pressure from Lehava, a new instruction was issued in October 2013 by the director of Israel's National Service Administration, Sar-Shalom Jerbi. According to this instruction, Jewish women who volunteer in hospitals, as part of their army service, will not be allowed to do night shifts, in an attempt to prevent them from developing intimate relations with Arab doctors. In recent years, especially in areas where Arabs and Jews interact regularly, members of the public and concerned parents have organized routine patrols to tackle such 'undesirable relationships' in an attempt to minimize their occurrence. Such patrols visit malls, high-streets and public parks on a regular basis in an effort to stop any interactions between Jewish young women or girls and Arab men and boys. Local authorities' regulations prohibiting non-residents from congregating in residential areas or making loud noise during night hours are used against Arab men ${ }^{5}$ in an attempt to limit their access and movement in Jewish areas. Protest marches were held in several cities in recent years to rail against these 'foreign men' who 'steal our daughters'. Arab men have been assaulted at several of these events due to being involved in such relationships ${ }^{6}$. The Israeli Knesset enhanced this moral panic by holding several special discussions on the issue, including two emergency meetings ${ }^{7}$.

In line with the ideas emanating from the moral panic literature, I will analyse the claims made by the different moral entrepreneurs and counterparts who take part in its creation. Many of these entrepreneurs have presented their views during discussions in several Israeli Knesset parliamentary committees and the Knesset plenary assembly sessions during the last decade. I will analyse these discussions as well as media representations and academic discussions about the topic which have also played a key role. The presentation of the findings will be divided into two sections. In the first section I will analyse the way in which the 'other men' - the 'folk devils' (Cohen, 1972) of this story - are presented, and the attempts to criminalise their behaviour. In the second section I will analyse the way in which 'our girls' are presented. As I will show, reconciling the commitment to Jewish values, including the prevention of assimilation with the commitment to democratic values, is not simple. I will show how the diagnostic category - 'girls at risk'- and the therapeutic discourse, which are used in these cases enables keeping this balance.

Jewish-Arab Mixed Relations in Israel: the context 
It is necessary to describe more broadly the context in which the relations between Jewish women and Arab men take place. The first crucial point to mention is that as a minority religion Jews are very concerned about assimilation. Well-planned segregation between Jews and Arabs, justified by the continuous conflict between the two groups, minimizes this option. Arabs continue to be seen as both fellow citizens and the enemy. This segregation is further entrenched through the separate State-funded schools systems. Arabs and Jews largely live in Jewish or Arab-only villages, cities or towns, with only few mixed cities, towns or villages. In most of the mixed areas, Arabs and Jews have separate areas. Most Israeli Jewish youth finishing high school are drafted to the Israel Defence Force (IDF). Based on the perception of Arabs as a potential security threat, they are largely exempted from army service. During their service, Jewish Israeli youth are likely to interact with Arabs, but such interactions only intensify the suspicion between these groups. Unsurprisingly, the labour market follows this pattern and is also highly segregated. As a result, the interaction between these groups, especially between young people, is very limited. Overstepping these borders through a romantic relationship becomes impossible and inconceivable for most Israelis. When despite these barriers such romantic relations are formed, the Israeli-Arab conflict has a lasting influence on them. Developments in recent years may redress the opportunity for interethnic contact, as more Arabs attain higher education and mix with Jews both in college and in the workplace (particularly in medicine, pharmacies and high-tech industries). Also, while Arabs are exempt from the military draft, they can serve as volunteers and many subgroups (Druze and Bedouin in particular) do serve. As a result, the settings where young Jews and Arabs can meet socially are growing larger, potentially "aggravating" the "problem" of mixed relationships.

The massive immigration to Israel from Ethiopia (since 1984) and the former USSR (since 1989) has contributed to the increase in the number of such relations. Over 1 million immigrants arrived from these countries to Israel based on the Law of Return ${ }^{8}$. Of these, about 300,000 immigrants were regarded as having 'Jewish ancestry' and therefore, based on the Law of Return, were eligible to immigrate, but at the same time, were not 'sufficiently Jewish' according to Orthodox Judaism (Sheleg, 2004). As marriages in Israel are arranged only by religious courts, and Orthodox Judaism controls all Jewish religious courts, these immigrants may not marry other Jews through this system and suffer extreme marginality. According to official data mixed couples are about $5 \%(100,000)$ of all married couples in Israel ${ }^{9}$. These couples were married outside of Israel. In most of these cases, the non-Jewish partner had a Jewish father or grandfather who married a non-Jew.

The response to such mixed couples largely depends on the ethnicity, class, religion and age of those involved. There are several well-known Ashkenazi ${ }^{10}$ middle class women who are in the arts or media and have Arab male partners ${ }^{11}$. These successful women aren't at the centre of the debate and their self-determination isn't questioned. The response is very different when these are Jewish women from lower socio-economic backgrounds. Simultaneously, Christian-Arab male partners are seen in a better light 
compared to Muslim-Arabs, and when there is a significant age gap, the resistance is stronger.

\section{Jewish-Arab Mixed Relations in Israel in the Academic Literature}

Jewish-Arab mixed relations is an under-researched area. The few important contributions include a historical precedent from the 1930s-1940s in Tel Aviv (Razi, 2009), an analysis of discourses and representations of interfaith relations (Carmi, 2014; Morag 2010; Stein 2010; Yosef 2002), as well as analysis of some of the barriers created by the State, including by law and social services. Triger's (2009) study examines the cultural and legal aspects of inter-faith marriages in Israel. As he explains, Israeli law doesn't directly prohibit such marriages, as it is committed to both Jewish and democratic values simultaneously. Instead, the issue is assigned exclusively to religious courts who will marry such couples. No alternative procedures or mechanism is in place for conducting civil marriage. Not prohibiting such marriages directly, as Triger rightly points out, doesn't decrease the validity of the prohibition, "but only makes it invisible and thus renders it absent from public discourse", (Triger 2009, 481).

A few researchers have examined the actual relationships between Arab men and Jewish women (Abu-Rayya 2000; Roer-Strier and Ben Ezra 2006; Cohen-Golani 2011; Racin and Dein 2010) or Arab-Israeli men and Western Christian women (Abu-Rayya 2007; Roer-Strier and Ben Ezra 2006). They shed some light on the experiences of these couples and their difficulties. They also make clear how politically loaded this topic is and the undeclared biases of some of the researchers (Cohen-Golani 2011; Keysari's $2000)^{12}$.

\section{Moral Panics, Youth and Social Work}

I will now present the theoretical framework which will help me analyse my data. Written more than 40 years ago, Moral Panic theory still attracts a lot of attention and its ideas are regularly used, developed and debated by scholars in varying fields (Altheide, 2009; Critcher, 2008; David, Rohloff, Petley \& Hughes, 2011). Special issues on this topic were recently published in the British Journal of Criminology (2009) and in Crime, Media, Culture (2011), as well as a special collection published by Ashgate (Krinsky, 2013).

Still the most frequently used definition of moral panic is taken from the opening paragraph of Stanley Cohen's book Folk Devils and Moral Panics (1972), which started a long and rich academic debate on this subject:

"A condition, episode, person or group of persons emerges to become defined as a threat to societal values and interests; its nature is presented in a stylised and stereotypical fashion by the mass media; the moral barricades are manned by editors, bishops, politicians and other right thinking people; socially accredited experts pronounce their diagnoses and solutions; ways of coping are evolved or (more often) resorted to; the condition then disappears, submerges or deteriorates and becomes more visible. Sometimes the object of the panic is quite novel and at other times it is 
something which has been in existence long enough, but suddenly appears in the limelight. Sometimes the panic passes over and is forgotten, except in folk-lore and collective memory; at other times it has more serious and long-lasting repercussions and might produce such changes as those in legal and social policy or even in the way society conceives itself", (Cohen, 1972: 9).

Cohen has taken pains to point out that 'the argument is not that there is 'nothing there' ... but that the reaction to what is observed or inferred is fundamentally inappropriate" (2002: 172). In other words, there is 'disproportionality': a sense that a more sizeable number of individuals are engaged in the behaviour in question than is actually the case (Goode and Ben-Yehuda, 1994: 36). Cohen also explains that every moral panic has its 'folk devils': "a person or a group of people... onto whom public anxieties are projected. For Cohen, 'folk devils' are susceptible to recognition as 'unambiguously unfavourable symbols'” (Hier, 2008: 176). What Cohen and many others who used his ideas seem to agree on is that, although the folk devils are the identifiable cause of moral panics, they often actually serve to hide the real cause of panic which is to be found elsewhere.

According to some of the key criticisms about Cohen's moral panic, the original theory didn't recognise the important role played by counter-discourses, narratives of opposition and the immense fragmentation of audiences as well as that of the media (Critcher, 2008; Hier, 2008; McRobbie \& Thornton, 1995). New scholars have shown how these issues come into play in determining if and how moral panic is developed. As I will show in this article, some of the arguments that are presented as part of this moral panic are forcefully rejected by major parts of Israeli society and media, while others are more easily adopted. Arguments using a psychological terminology and presented by professionals seem to be especially effective in this context. My analysis will aim to explain these differences.

In another contribution to the moral panic literature, Thompson $(1998,44)$ explains why major parts of the moral panic literature continue to focus on youth cultures:

"No age group is more associated with risk in the public imagination than that of 'youth'... Youth may be regarded as both at risk and a source of risk in many moral panics. This is not surprising in view of the transitional status of this age group, occupying a position between childhood and adulthood".

Connected with the enhanced focus on youth, a series of recent publications explored more closely the connection between social work child protection and moral panics (Smith, Cree \& Clapton, 2012; Clapton, Cree \& Smith, 2013a; Clapton, Cree \& Smith, 2013b; Warner, 2013). These publications concluded that a close reading of the foundations of social work indicates that a tendency to both react to and participate in moral panics is a persistent feature of social work but especially child protection (Clapton, Cree \& Smith, 2013b). Indeed the young women discussed in this article are often presented by social workers and other psych professionals as child-like, lacking in judgement and as young people at risk that should be safeguarded.

Methodology 
The data presented in this study is secondary. A major source that I will use is transcripts from Israeli parliamentary committee meetings in which the topic was discussed by the different delegates who attended these meetings. I will also analyse and relate to media, artistic and academic representations of the topic. In line with the moral panic literature I analyse how different moral entrepreneurs present the topic and then how these messages are being enhanced and disseminated further by the media.

The analysis started by identifying the main recurring themes within the data. The clearest themes to emerge were 'Arab men' and 'Jewish women' and I will focus on these. Other themes were the relations between these men and women and the children that come or might come as a result. The next stage of analysis required a closer inspection of the language, terminology and imagery used in discussing these relations. I was particularly attentive to the ways in which the behaviour of these men and women was interpreted and analysed and the ways in which it was described.

\section{The Demonization of Arab Male Violence}

The most vocal objection to Jewish-Arab couples comes from Jewish religious groups on the grounds that such marriages are a grave sin according to Jewish law. But as they mainly address non-religious Jews, these religious opponents rarely use religious arguments. The arguments used by the Haredi (Jewish Ultra-Orthodox) NGO Yad Le'achim are a good example. Such arguments, imbedded in negative portrayals of Arab men, receive intellectual support from Israeli right wing academics such as Dr. Mordechai Kedar. Kedar is a lecturer at the Department for Arabic and a Research Associate at the Begin-Sadat Centre for Strategic Studies, both at Bar Ilan University. Kedar is an expert on Israeli Arab society ${ }^{13}$. As part of a conference on Violence against Women on the Backdrop of a National Conflict which was held at the Likud Party headquarters (Metzudat Ze'ev) ${ }^{14}$, Dr. Kedar gave the opening lecture titled "Is there a Cultural and Religious Background in Islam for Sexual Violence as Part of Fighting the Enemy?"15. The conference and Kedar's talk didn't focus specifically on Jewish women who are in relationships with Arab men but the topics are clearly linked. Kedar opens his talk by explaining that the use of sexual violence as part of a socio-political conflict has its roots in the pre-Islamic tribal communities and that Islam itself tried to uproot these tendencies with no success. In the tribal pre-Islamic culture, that, according to Kedar, still dominates the Arab world, especially in the Middle East and despite many hundred years of Islam, the woman was and still is seen today as "an object, a sex doll that exists to satisfy man's urges". In the 20 minute lecture Kedar reviews a series of cases of sexual violence in contexts of war and socio-political conflict, starting with Muhammad's wife, Safiyya bint Huyayy whose tribe was defeated and its women captured, to contemporary internal tensions in Iraq, Darfur and Israel. In all of these cases, according to Kedar, the same unchanging pre-Islamic tribal culture is the main source of influence responsible for the use of sexual violence against women. This culture is often 'swept under the carpet' and only reveals its true nature in times of 
crisis. Victory or defeat, in this culture, has to be total. "Conflicts aren't settled in an agreement but with the total destruction, pillaging and obliteration of the losing side... and the ultimate victory is when you also humiliate your enemy and the ultimate humiliation is when you rape your enemy's daughter, if possible before his own eyes". According to Kedar this culture also shapes the way Arabs in Israel treat Jewish women, 'the more and the less righteous', both suffer. Before criticising Kedar it is also important to mention that sexual violence is used and has been used in many national, inter-ethnic and inter-religious conflicts, in different places and times. In some cases, it was suggested as a possible weapon for Arab Palestinian men in their struggle against Israeli occupation ${ }^{16}$.

The problem with Kedar's lecture isn't its topic but the sweeping generalizations he makes about millions of Arabs across many different countries, cultures and periods. He portrays Arab culture as static and unchanging across time and place. In this cultural essentialism, the root cause of the negative characteristics is not biology, but a specific culture, which is presented as uniform and fixed across time and place (Barker, 2002; Donald and Rattansi, 1992; Grillo, 2003). This questionable social science is extremely influential, especially in right-wing circles, and similar arguments are repeated in many different forums.

An example of how a variation on such views is reflected in the discourse about the relationships between Jewish women and Arab men can be found in Yad L'achim's publications. Yad L'achim ('A Hand to Our Brothers' in Hebrew) is a Haredi (Jewish Ultra-Orthodox) NGO that is devoted to maintaining the borders of the Jewish community and strengthening its hardcore Ultra Orthodox centre. It recruits new members to the Haredi community, and attempts to prevent defection ${ }^{17}$ as clearly indicated in its official sub-title: "Not giving up on any Jew".

Firstly let's examine how the organization describes the way such relationships develop. This narrative, which appears in different variations in the material I analyzed, is presented in an 8-page booklet, entitled "A Story with a Sad Ending", printed in colour on chrome pages and distributed by the organisation to thousands of Israeli youths. On the front cover is the face of a woman covered by a Niqab ${ }^{18}$, with only her big eyes visible in the middle. The title points to what the story is about. It all starts with a gentlemanly gesture:

"He picks up her bag, they start chatting, and they go out on a date. He pays for everything, but hides the fact he is an Arab, at least for a while. When he finally tells her, her parents protest, but she knows one has to pay a price 'for love'; she leaves her parents for him, they get married."

According to Yad Le'achim's rhetoric, after the relationship is formalized by marriage, the men change and the woman's status degrades to that of a slave-she is locked up and isolated, her rights are minimized, and she needs to be totally compliant to the demands of her husband and his family. Corporal punishment is the norm if she does 
not comply. After several years, when she decides to leave, she is told she has to give up the children.

Such stories seek to convey a single message which is stated at the end of the booklet: "you need to hear the truth ... there will be no happy ending here, only heartache." The reason for this inevitable tragic ending is clearly explained: "His culture is very different from your free and liberated life... From the moment you are 'his' you lose control."

Yad L'achim's rhetoric also presents Arab men as devious tricksters. They steal money and goods which they use as bait while also pretending to be Jews to attract young innocent Jewish girls. This attempt to pass as Jews, "challenges the notion that Jewish Israeli identity is an innate, unchangeable essence, thereby questioning the privileges on which Jewish Israeli racial subjectivity is founded", (Yosef, 2002: 554). On top of this very negative and generalizing portrayal of Islam and Arab culture which is soaked with cultural essentialism, this discourse totally ignores the patriarchal character of Jewish religion, especially in its Orthodox and Ultra-Orthodox interpretations.

\section{The Legal Path: Criminalization of the Advances of Arab Men}

Many of the parliamentary committees that I reviewed held discussions about how to respond to the advances of Arab men. Representatives of NGOs, professionals and politicians who are involved see these advances as criminal and would like the law to prevent them. As an example of such views and attempts I will mention the emergency meeting ${ }^{19}$ held on $8^{\text {th }}$ December 2011 to discuss the mass 'kidnapping of new immigrant teenage girls by members of minority groups'. Member of Knesset (MK) Danny Danon, the committee's chair, started the meeting declaring:

"This is an emergency meeting. We were all exposed to very frightening evidence of the troubling rise in the number of cases of young women from low socio-economic backgrounds that are simply being kidnapped... in broad daylight in Kiryat Malachi, Arad, Beer-Sheva, Naharia, and that [men from] minority groups are simply forcing girls into cars [my emphasis, Y. Hakak]. This is a scary phenomenon. It is important to mention that most of the cases aren't cases of physical kidnapping. Most of the cases are such in which a romantic relationship is being developed, based on an economic need and luring of these girls, most of them new immigrants".

During that meeting MK Danon invited Alina Zanani, the head of the social work team at the Yad Le'achim organisation, to share with the committee the data her organisation gathered. Zanani said:

As we see it, kidnapping is an extreme case of a widely spread phenomenon in Israel that we deal with daily. We have over 1000 cases reported to us every year... and this phenomenon is growing. We are talking about a system of, as you called it - temptation. It starts with temptation but these relationships turn to be ones of abuse, hurt and coercion.

The fact that Yad Le'achim is a Haredi (Jewish Ultra-Orthodox) organisation dedicated to fighting Jewish assimilation didn't prevent most committee members from trusting its data or how the organisation interpreted it. Shortly after the meeting began MK 
Danon asked the Israeli Police representative, inspector Rachel Gribben ${ }^{20}$ to present the police perspective. The inspector's response was clear: “the police isn't familiar with such a phenomenon... we have had very few cases that were examined which can be described in a similar way to your description... but we are not familiar with such a phenomenon" 21 . This response raised an outcry from the only centre-left delegate who took part in the meeting, MK Daniel Ben-Simon from the Labour party who left after several minutes in protest. Other committee members criticised the police for not being aware of reality ${ }^{22}$. Following the angry response of MK Ben Simon and the 'disappointing' response of the police delegate who didn't confirm the claims regarding a massive 'phenomenon' reaching 1000 cases a year, some of the participants tried to better explain what they think is happening. Ben-Tzion Gupshtein, the head of Lehava organization said:

"We are not talking about physical abductions in which someone is taking a girl by force into their car. We are talking about kidnapping, about temptation. Just like we have a law that says that sex with a minor ${ }^{23}$, even if they are willing, is forbidden, the same is needed here. The moment they 'buy' the girl with (a can of) coke, pizza, 500 shekels or a mobile phone and she is a minor - this is kidnapping. Indeed they don't take her by force, and you will ask her - she's fine... 'He gives me, why shouldn't I use him...' and when the family calls the police and the police calls the girl, the girl says 'why not? I love him'”.

I suggest understanding these arguments as part of an attempt - unsuccessful so far - to address this issue legally by criminalizing Arab men. Not less important was the fact that despite the police response, right wing newspapers and media reported the following day with headlines about 1000 cases of kidnapping and temptation of female minors by men from minority groups. This event is just one of the peaks in a successful campaign to create moral and sexual panic.

According to Herdt, "sexual panics today are among the most pivotal mechanisms political, economic, and religious - that reproduce structural violence of all kinds: they serve to embody fear, disgust and social exclusion in speech, meaning and practices" (Herdt 2009, 18). These panics provoke a cultural anger in the service of moral regulation that targets the vulnerable in society. Moral panics also expose the "ideologies, hierarchies and social fissures of societies, typically registered, as with many human phenomena, along the lines of systematic forms of structural violence" (Herdt 2009, 18). As this panic increases so are the chances that other "more reactive mechanisms of surveillance, regulation, discipline and punishment will be employed" (Herdt 2009, 1).

In this case as in other occasions, the attempt to create moral panic and to criminalize Arab men ${ }^{24}$ received extremely critical responses from the more moderate and left wing media and MK Danon was severely criticised for the racist messages his committee was sending out ${ }^{25}$. Probably the most extreme expression of the way Danon's committee was looked at in the political left is its satirical-theatrical adaptation. The whole 
committee protocol was performed verbatim with minor comical additions ${ }^{26}$ by the alternative theatre group 'Teatron Haziti'27. It is clear that both the audience and the actors found the actual transcript of the committee meeting to be completely farcical and totally racist.

But even if this moral/sexual panic leads to further attempts to address this issue legally, it will not be simple, as if interfaith marriage will be presented as forbidden through legislation, or by education or any other means, it is likely to alienate Jews and be counterproductive. This is a structural problem typical to the enclave and "any attempt to impose penalties will merely make the membership melt away even faster" (Douglas, 1992, 138).

\section{Passive Foolish Girls: It can't be Real Love}

As I showed so far, the discourse presenting Arab men as violent and dishonest predators and the attempt to criminalise them or prevent such mixed faith relations legally were forcefully rejected by many Israelis as racist and anti-democratic. For these reasons, I argue, the different entrepreneurs focus their discursive efforts on Jewish women and girls. The current debate in Israel mainly concerns the relations of young Jewish women and girls, from low socio-economic backgrounds, with Arab men. What motivates these girls to get into these relationships, which the different speakers (politicians, police delegates, social workers etc) see as so negative and dangerous? When there is even a suspicion that a girl is being solicited for prostitution, especially when the girl is a minor, the legal system has clear ways to deal with the problem and with the man involved, be he Jew or Arab. But this applies to very few cases. In most cases, there is no such evidence or even suspicion yet the different state agencies, be they related to welfare and social work or the police and the legal system, are still very unsympathetic, to say the least, towards these couples and often try to separate them against their will.

One of the recent discussions on the issue took place in the Knesset assembly itself in response to a motion for the agenda ${ }^{28}$ by Shas $^{29}$ delegate MK Avraham Michaeli ${ }^{30}$ about 'the assimilation trend: Jewish girls living in Arab villages'. In response, Mr. Moshe Cahlon, the Minister of Welfare and Social Services said the following:

"This trend of Jewish girls being abused by men is one of the end points in their downwards journey as girls at risk ... We are talking about girls in distress and it is sad to say but sometimes a bit of warmth, a pack of 'Marlboro' and a coke - she can give her body. And after she has done it once or twice she loses the emotional [barrier], and please note where it all starts: a little bit of warmth and attention that she is apparently missing, and then she slides down this slippery slope into the abyss", (01.10.2012, Knesset session 307). 
According to the minister, these girls, who he defines as 'at risk', are very easily tempted. A pack of Marlboro, a can of coke and a bit of warmth would be enough to convince them to get their clothes off or marry an Arab. These portrayals of Jewish girls as foolish, extremely childish and easily tempted repeat themselves in many other parliamentary discussions on the topic. At the base of this view is also the belief that these relations aren't motivated by 'real love'. This perception was expressed, for example, by Ben-Tzion Gupshtein, the head of Lehava organization ${ }^{31}$ who was invited to speak before the Knesset Committee for Immigration, Absorption and Diaspora Affairs at an emergency discussion about 'the kidnapping of immigrant girls by men from national minority groups'32. This is what he said:

"The problem is that they are there by choice. They don't understand, they think they love him... they don't know that they want to get out... They live under the influence of the drug of love, they think they feel good... among new immigrants it is much more common as they are poor... they want to be given more and they also don't know the differences - who are Arabs, who are Jews, they don't know this problem, meaning they all look the same... so 'who gives more', one girl told me... 'the Jews don't know how to pamper, Arabs pamper very well'... he gives them, pampers them and that's what they are missing outside, affection and love".

The immigrant girls have a false consciousness. They think they love these men, they think they feel good, but they don't. It isn't clear on what grounds these claims are made and we can only assume that the speaker refers to these girls' lack of touch with their true and 'real' Jewish identity and 'divine spark', as if they were in touch with it, they would clearly avoid such relations. This bad judgement is also a result of their naivety and lack of awareness of the differences between Jews and Arabs who look the same to them. Whereas in previous sections Arab men were presented as violent and deceitful, here their threat to Jewish masculinity stems from their ability to be more giving and pampering towards women.

\section{Girls from Broken Homes who are 'at Risk'}

Since portrayals of Jewish women as foolish and weak are also often criticised by Israeli feminists, the psychological discourse becomes especially useful. This is why social workers, psychologists and other representatives of the psych-professions (Rose 1996) are asked to intervene.

In 2006 the State Comptroller published his report about the treatment of girls at risk by different State agencies. One of its last sections deals with girls at risk who befriended Arab adults. As part of this investigation the report quotes the head of the Department of Girls at Risk in Kiryat Gat municipality who explained the reasons that motivate girls to look for the company of these adults:"Low self-esteem, lack of warmth and rejection by the family unit, parents out of the house due to long working days". Without clearly stating it, it is suggested that we need to understand these relationships as an outcome of parental neglect, rejection and abuse that these girls have experienced. 
These arguments were brought up in many parliamentary committees which dealt with the topic in recent years. This is how Alina Zanani, the head of the social work team at the Yad Le'achim organisation, described these girls during a meeting of the Parliamentary Committee on the Status of Women which took place as part of Jewish Identity day ${ }^{33}$ :

"As part of the therapy the girls go through we check thoroughly what led the girl to such a relationship. In most cases we find out that these girls had very difficult backgrounds of deprivation, sexual abuse, family traumas such as very difficult divorce of the parents, violent homes, severe financial difficulties, and the relationship with the Arab partner wasn't a result of the girls' choosing it, out of the an idyllic wish to unite the two nations. It is a relationship that is created out of the girl's attempt to run away [from her own reality] and without all of the other factors of neglect and difficulty this relationship wouldn't have been created".

A few months later during the emergency meeting mentioned earlier due to the growing number of 'kidnaps' of Jewish girls by men from national minority groups, Alina Zanani added the following details:

"We are talking about weak women and girls who need protecting... Women and girls with weak personality, lacking judgement, with very limited ability to identify when they are being abused and resist it... and the role of the immigration committee to my mind is to identify these groups and build the appropriate services to inform and treat them".

According to Zanani, a Jewish girl will not date an Arab because she likes him. Choosing an Arab partner is just a symptom of her emotional problem. Not only that, but due to these emotional problems, the girls lack an ability to understand when they are abused and are therefore 'at risk', and require protection by the state through social services. Depicting 'other men' as dangerous, deceitful and violent, and Jewish women as weak victims unable to protect themselves provides justification for intervention and helps maintain the separation between communities. Like in some other cases (Clapton, Cree \& Smith, 2013), the moral panic in this case financially benefited some of its promoters and by doing so resulted in neglecting more burning issues. ${ }^{34}$

\section{Discussion and Conclusions:}

The attempts to create moral panic regarding the problematic relations between Jewish women and Arab men presented in this article expose an anxiety shared by many Israeli Jews about the possibility of Jewish assimilation and loss of Jewish identity. I have analysed the claims made by the different moral entrepreneurs including right wing and religious organisations, Israeli Knesset members, journalists and others. Arab men are presented by these entrepreneurs as deceitful and inherently violent while at the same time they are also presented as very warm, affectionate and better able to pamper women compared to Jewish men. As I have shown, the attempt to portray Arab men as violent and abusive predators and the attempt to criminalise their behaviour or prevent 
them legally from developing relations with Jewish women and girls were all rejected forcefully by the political left as racist and undemocratic. Forcing Jews to avoid such relations by law is also likely to be counterproductive and increase defection from the Jewish enclave. I have suggested that for these reasons those resisting inter-faith relations shift the emphasis of their arguments to focus on Jewish women and girls in such relations, presenting them as weak and passive victims who need to be rescued. Since such arguments are often also criticised by Israeli feminists, those opposing interfaith relations resort to professional psychological discourse. While contemporary scholars who developed Cohen's ideas showed how often moral panic claims are rejected and opposed, the adoption of professional psychological discourses as a tool of gaining leverage in these debates was not yet explored. The psychological discourse provides 'scientific' and 'objective' tools for 'diagnosing' specific women as having emotional problems. Based on this discourse, these young child-like women and girls require safeguarding 'for their own interest'. This professional discourse presents itself as making objective truth claims, for the benefit of the Jewish women and girls, and so far it hasn't been subjected to critical examination. Since this professional psychological discourse and its related practices are not considered to violate democratic principles it transcends controversy and scepticism, while still enjoying high credibility(Rose 1996). Both moral panic and the psychological discourse employed distract attention from the social circumstances affecting 300,000 immigrants unable to marry through Israeli religious courts and suffering extreme social marginality, and present the issue as a series of cases of psychological dysfunction. Exploring this psychological discourse in greater detail will be at the centre of a different article (Hakak, 2015) but additional future research should urgently be conducted with men and women involved in such relationships, with social workers working with them, as well as representatives of the legal system that is also often involved in these interventions.

YOHAI HAKAK is a lecturer in the Department for Clinical Sciences at Brunel University. ADDRESS: Department of Clinical Sciences, Brunel University, Uxbridge, UB8 3PH, UK. Email: yohai.hakak@brunel.ac.uk

\section{Bibliography:}

Abu-Rayya, Hisham Motkal. 2000. "Psychological and Sociocultural Adjustment of Intermarried Jews and Arabs in Israel", MA dissertation: Hebrew University of Jerusalem •

Abu-Rayya, Hisham Motkal. 2007. "Acculturation, Christian religiosity, and psychological and marital well-being among the European wives of Arabs in Israel."

Mental Health, Religion \& Culture 10 (2):171-190. doi: 10.1080/13694670500504901 • Altheide, David. 2009. "Moral Panic: From Sociological Concept to Public Discourse". Crime, Media, Culture 5(1): 79-99.

Cahan-Stravchinsky, Paula, Liat Yorovich, Vatslav Konstantinov, and Ravit Efrati. 2005. Characteristics and Needs of the Girls Treated by the Service for Girls and Young Women. Jerusalem: Myers-Joint Brookdale Institute• 
Carmi, Ruth. 2014. What if an Arab would Hit On Your Sister: Racism and Gender in Israel, Jerusalem: The Reform Centre for Religion and State.

Clapton, Gary, Viviene Cree, and Mark Smith. 2013. "Moral panics and social work: towards a sceptical view of UK child protection." Critical Social Policy 33: 197217.

Cohen-Golani, Sarit. 2011. "... And I didn't know anything about Arabs at all... I was new to those things...": A phenomenological study of the experience of Jewish Girls who engaged in relationships with Aarab men, MA dissertation: Ben Gurion University of the Negev, Israel •

Cree , Viviene E., Gary Clapton, and Mark Smith. 2012. "The Presentation of Child Trafficking in the UK: An Old and New Moral Panic?" British Journal of Social Work, 1-16.

Critcher, Chas. 2008. "Moral Panic Analysis: Past, Present and Future". Sociology Compass 2(4) 1127-1144.

David, Matthew, Amanda Rohloff, Julian Petley, and Jason Hughes. 2011. "The Idea of Moral Panic - ten dimentions of dispute". Crime, Media, Culture 7(3): 215-228.

Douglas, Mary. 1992. Risk and Blame: Essays in Cultural Theory. New York: Routledge•

Hakak, Yohai. 2015. "Battling Against Interfaith Relations in Israel: Religion, Therapy, and Social Services." Journal of Marital and Family Therapy, DOI: $10.1111 /$ jmft.12123

Hazani, Moshe. 1989. "Deviant companionship and interaction across an intergroup "seam": Arab pimps and Jewish prostitutes." Plural Societies 19: 55-72.

Herdt, Gilbert H. 2009. Moral panics, sex panics: fear and the fight over sexual rights, Intersections: transdisciplinary perspectives on genders and sexualities: New York University Press •

Heir, Sean P. 2008. "Thinking beyond moral panic: Risk, responsibility and the politics of moralization". Theoretical Criminology 12: 173-190.

Krinsky, Charles. 2008. Moral Panics Over Contemporary Children and Youth, Surrey: Ashgate.

Krinsky, Charles. 2013. The Ashgate Research Companion to Moral Panics. Surrey: Ashgate

Keysari, Ofir. 2000. "Choosing a partner from a minority group (Bnei-Miutim) among girls at risk as a result of their attachment style and risk taking tendency", MA dissertation: Bar-Ilan, Ramat-Gan •

McRobbie, Angela and Sarah Thornton. 1995. "Rethinking 'Moral Panic' for a Multimediated Social World", British Journal of Sociology, 46(4): 559-574.

Mai-Ami, Naomi. 2008. Assimilation in Israel and Outside of it. Jerusalem: The Knesset Research and Information Centre

Morag, Raya. 2010. "Interracial (Homo) Sexualities: Post-Traumatic Palestinian and Israeli Cinema During the al-Aqsa Intifada (Diary of a Male Whore and The Bubble)." International Journal of Communication 4:932-954 •

Nitzan, Tal. 2009. The Limits of the Occupation: The Rarity of Military Rape in the IsraeliPalestinian Conflict, MA dissertation, Hebrew University of Jerusalem, Israel.

Racin, Limore, and Simon Dein. 2010. "Jewish-Arab couple relationships in Israel: underlying motives for entering and engaging in intermarriage." Journal of Muslim mental health 5 (3):278-300• 
Razi, Tammy. 2009. Forsaken Children: The Backyard of Mandate Tel-Aviv. Edited by Eli Shaltiel. Tel-Aviv: Am Oved•

Roer-Strier, Dorit, and Dina Ben Ezra. 2006. "Intermarriages between Western Women and Palestinian Men: Multidirectional Adaptation Processes." Journal of Marriage and Family no. 68 (1):41-55

Rose, Nikolas. 1996. Inventing our selves: Psychology, power and personhood. Cambridge: Cambridge University Press •

Smith, Mark, Vivian Cree, and Gary Clapton. 2012. "Time to be Heard: Interogating the Scottish Government's Response to Historical Child Abuse", Scottish Affairs 78: 124.

Stein, Rebecca L. 2010. "Explosive: Scenes from Israel's Gay Occupation." GLQ: A Journal of Lesbian and Gay Studies no. 16 (4):517-536•

Thompson, Kenneth. 1998. Moral Panics. London, UK: Routledge. Triger, Zvi. 2009. "The Gendered Racial Formation: Foreign Men, 'Our' Women, and the Law". Women's Rights Law Reporter 30, (3/4): 47 •

Yosef, Raz. 2002. "Homoland: Interracial Sex and the Israeli-Palestinian Conflict in Israeli Cinema." GLQ no. 8 (4):553-579.

Warner, Joanne. 2013. "Social Work, Class Politics and Risk in the Moral Panic Over Baby P", Health, Risk \& Society, 15 (3): 217-233.

1 The author would like to thank the editors and the two anonymous reviewers for their detailed comments and suggestions.

2 Lehava is an extreme-right Jewish-Israeli NGO dedicated to preventing Jewish assimilation. The organisation was severely criticised (but not banned) when the police arrested and convicted three of its affiliates for setting fire to the Jewish-Arab bilingual school in Jerusalem on 29 November 2014. For more see an article in The Times of Israel by Judah Ari Gross from 14 April 2015.

3 Ahmed as a distinctly Arab name, and Sara as a Jewish name.

4 for more please see the article in Walla by Yehoshua Brayner from 01.08.2010 titled 'a right wing campaign: your grandchild will be called Ahmed Son of Sara'?

5 As an example see pages 32-33 in the protocol of the Knesset Committee for Immigration, Absorption and Diaspora Affairs held on 28 December 2011.

6 For more see an article in Ha'aretz by Gideon Levi \& Alex Libak (4.5.2013) titled “Don't Touch our Girls".

8 For more about the activities of the different religious right wing organizations involved please see Carmi (2014).

8 The Law of Return is part of Israeli legislation, passed on 5 July 1950. It gives Jews the right of return and the right to live in Israel and to gain citizenship. In 1970, the right of entry and settlement was extended to people of Jewish ancestry and their spouses. In this category of 'being of Jewish Ancestry' are included, in addition to those born as Jews (having a Jewish mother or maternal grandmother), also those having a Jewish father or grandfather 'only', and converts to Judaism.

9 Please see Mai-Ami (2008).

10 Askenazi Jews are Jews of central or Eastern European origin or ancestry.

11 Such as Dana Modan and Kais Nashef or Yael Ronen and Yousef Sweid.

14 For a more detailed review of the studies on inter-faith relations in Israel, please see Hakak (2015).

15 Kedar served for twenty-five years in IDF Intelligence Corps where he focused on Islamic groups, the political discourse of Arab countries, the Arabic press and mass media, and the Syrian domestic arena. 
14 The conference took place on 22.11.09 and was organised by the Zionist Women's Forum. 15 The lecture can be viewed on Youtube: https://www.youtube.com/watch?v=_PB2eTNA94\&list=FL6AWN8o40lRzMjucTi7cXPg 16 For example, the Egyptian lawyer Nagla El-Imam suggested in an interview broadcast on 31 October 2008 on Al Arabiya TV that Palestinian men should sexually harass Jewish Israeli women as a form of resistance to Israeli occupation, http://www.youtube.com/watch?v=nDqWGtykYNE. For a study about rape in the Israeli army, see Nitzan (2009)

17 Yad L'achim was founded in 1950 by a group of Haredi activists from a variety of sub-groups within the Haredi community. It initially focused on integrating immigrants into religious educational and communal frameworks. (see http://www.yadlachimusa.org.il/)

18 The Niqab covers the face. It is worn by many Muslim women across Saudi Arabia, the Indian subcontinent as well as by many women in the West.

19 This was a meeting of the Parliamentary Committee on Immigration, Absorption and Jewish Diaspora 20 From the Victims of Crime Section, the Ministry for Internal Security.

21 In a later TV interview on Channel 10 London et Kirshenbaum, Dannon was armed with police reports about a few such cases.

22 One of them was MK Anastasia Michaeli from Yisrael Beiteinu who said: 'I'm ashamed that the police can't provide appropriate data'.

23 In Israel, 14 is the age of consent. Sexual relations under this age are forbidden by law.

24 Criminalizing Arabs is a well-documented strategy in Israeli society and is well documented. For more on this please see (Elbaz, 2013).

25 See as an example his interview at the Channel 10 program London et Kirshenbaum on 29.12.11: http://lnk.nana10.co.il/Article/?ArticleID=855930

26 The performance was called 'The Invasion of the Immigrants' Snatchers' after the well known horror film 'The Invasion of the Body' Snatchers'.

27 Which could be translated as 'Frontal Theatre'.

$28 \mathrm{~A}$ motion for the agenda is a preliminary a debate concerning the inclusion of an issue raised by an MK on the Knesset agenda. A parliamentary question is asked by an MK of a minister on ministry affairs, to draw the attention of the Government and the public to an issue that, in the presenter's opinion, needs corrective action. Parliamentary questions are presented in writing, and the minister must reply in the Knesset plenum within a period of time set by Knesset bylaws.

29 Shas is an ultra-orthodox religious political party in Israel, primarily representing the interests of religiously observant Sephardic and Mizrahi Jews.

30 Michaeli immigrated from Kulashi in the USSR (today Georgia) in 1971 when he was 14 . Many of the girls who develop such relationships come from former USSR countries which were under strong Islamic influence.

31 Lehava (meaning flame) in Hebrew is also the acronym for 'Prevent Intermarriage between Jews and non-Jews and that's the stated and official aim of this organisation.

32 Date of that meeting?

33 That was held in the Knesset on 8 Feb, 2011

37 For more on these issues please see the news article by Shay Grinberg and Uri Blau in Ha'aretz from 7 May 2011 titled 'Cahana Lives Comfortably'. 